Int. J. Electrochem. Sci., 14 (2019) 10720 - 10728

\title{
Graphene/Polyaniline Nanocomposite as an Electrochemical Sensor for Ultrasensitive Detection of $\mathrm{Pb}(\mathrm{II})$
}

\author{
Liting Wei ${ }^{1, *}$, Lei Fan $^{1}$, Haiying Yang ${ }^{1}$, Yangfang $W u^{1}$ \\ Department of Applied Chemistry, Yuncheng University, Yuncheng, 044000, China \\ *E-mail: weiliting_job@163.com
}

doi: $10.20964 / 2019.12 .56$

Received: 2 July 2019 / Accepted: 27 September 2019 / Published: 29 October 2019

\begin{abstract}
This work describes the development of an electrochemical sensor for the ultrasensitive detection of $\mathrm{Pb}$ (II) using a graphene/polyaniline (GN/PANI) nanocomposite electrode prepared by a reversephase suspension polymerization technique in the presence of polyvinylpyrrolidone (PVP). The obtained GN/PANI nanocomposite was characterized by scanning electron microscopy (SEM) and Fourier transform infrared (FT-IR) spectroscopy. The electrochemical behavior of lead ions $\left(\mathrm{Pb}^{2+}\right)$ was determined by cyclic voltammetry and differential pulse voltammetry. The GN/PANI nanocomposite showed evidence of increased surface area under SEM. The GN/PANI-modified electrode exhibited high electrochemical conductivity, producing a four-fold increase in peak current (vs. the unmodified electrode). The largest current response was obtained when the weight fraction of graphene was $0.49 \%$. A linear working range of $1.0 \times 10^{-9}$ to $1.0 \times 10^{-4} \mathrm{M}$ was established between current and $\mathrm{Pb}^{2+}$ concentration with detection limits $(\mathrm{S} / \mathrm{N}=3)$ of $0.06088 \mathrm{nM}$. The large specific surface area, satisfactory repeatability, long-term stability and simple synthesis promote the GN/PANI nanocomposite as a promising electrochemical sensorfor the determination of $\mathrm{Pb}^{2+}$.
\end{abstract}

Keywords: Heavy metal; Reverse-phase suspension polymerization; Graphene/polyaniline nanocomposite; electrochemical sensor

\section{FULL TEXT}

(C) 2019 The Authors. Published by ESG (www.electrochemsci.org). This article is an open access article distributed under the terms and conditions of the Creative Commons Attribution license (http://creativecommons.org/licenses/by/4.0/). 